\title{
FLUXOS TRANSNACIONAIS E ESPAÇOS EM RECONVERSÃO ECONÔMICA: ANÁLISE DO CASO DO MUNIĆ́PIO DE SÃO JOÃO DA BARRA, RJ
}

\author{
TRANSNATIONAL FLOWS AND AREAS IN ECONOMIC RECONVERSION: CASE ANALYSIS OF THE MUNICIPALITY OF \\ SÃO JOÃO DA BARRA, RJ
}

\section{RESUMO}

O texto tem como objetivo analisar o papel do Complexo Portuário e Industrial do Açu em seus aspectos econômicos no município de São João da Barra, RJ, sede do complexo. A elaboração do texto baseou-se, além de pesquisa bibliográfica e documental, em dados de pesquisa de campo, a qual teve como objetivo o levantamento do perfil das novas empresas que se localizaram no porto, suas relações econômicas com a região e seu relacionamento com as administrações locais. Os resultados deste levantamento indicam que, dada a complexidade das operações por elas desenvolvidas, as relações comerciais com empresas locais são frágeis, especialmente os gastos com a aquisição de equipamentos e mão de obra especializada, que não foi nem será tão cedo contratada localmente, o que limita, e muito, a capacidade indutora desses investimentos sobre a economia local/regional. Por meio das respostas dos representantes do setor público, é possível concluir que, nos municípios da região, há virtual ausência de políticas públicas de longo prazo voltadas para o desenvolvimento; que os seus interlocutores são frágeis perante as grandes corporações e os governos locais desprovidos de visão estratégica enquanto formuladores de políticas públicas.

Palavras-chave: Porto do Açu. Desenvolvimento. Emprego. São João da Barra.

\begin{abstract}
The text aims to analyze the economic role of the Açu Port and Industrial Complex in the municipality of São João da Barra, state of Rio de Janeiro, Brazil, where the Complex is located. Besides bibliographic and documentary research, the study was based on field survey data, which goal was to identify the profile of the new companies located in the port, their economic relations in the region, and their relationship with local governments. Results indicate that, given the complexity of their operations, commercial relations with local companies are fragile, especially those expenses with the acquisition of equipment and skilled labor, which was neither hired nor will be hired locally so soon, which greatly limits the capacity to induce these investments in the local/regional economy. From the responses of the public sector representatives, it can be concluded that, in the municipalities of the region, there is a virtual absence of long-term public policy focused on development; that their interlocutors are fragile in relation to large corporations, and local governments lack strategic vision as public makers.
\end{abstract}

(D) Rosélia Piquet ${ }^{a}$

(D) Hevilmar Carneiro Rangel ${ }^{a}$

Dichard de Castro ${ }^{a}$

a Universidade Candido Mendes (UCAM), Campos dos Goytacazes, RJ, Brasil

DOI: $10.12957 /$ geouerj.2020.48416

Correpondência: ropiquet@terra.com.br

Recebido em: 18 set. 2019

Revisado em: 21 out. 2019

Aceito em: 20 dez.2019

Keywords: Açu Port. Development. Jobs. São João da Barra. 


\section{INTRODUÇÃO}

O texto tem como objetivo analisar o papel do Complexo Portuário e Industrial do Açu em seus aspectos econômicos no Município de São João da Barra, RJ, sede do complexo. Tendo em vista que empreendimentos de grande porte como os do Porto do Açu provocam impactos profundos nos locais de sua implantação, causando uma verdadeira ruptura com o contexto econômico, social e ambiental anteriores à sua chegada, o texto procura analisar as relações estabelecidas entre o empreendimento, o município e a região em que se localiza.

A forte demanda internacional de commodities agrícolas e minerais, aliada ao desaparelhamento dos portos públicos brasileiros, levou a modificações na legislação portuária, permitindo que a iniciativa privada construísse e operasse terminais privados no país. O Porto do Açu é o primeiro terminal privado proposto e em operação no Brasil.

A elaboração do texto baseou-se, além de pesquisa bibliográfica e documental, em dados de pesquisa de campo, que teve como objetivo o levantamento do perfil das novas empresas que se localizaram no porto, suas relações econômicas com a região e seu relacionamento com as administrações locais. A pesquisa de campo foi desenvolvida por meio de entrevistas semiestruturadas com altos administradores das empresas e com lideranças municipais, o que permitiu o conhecimento de dados inéditos sobre o Complexo Portuário.

No primeiro item do texto apresenta-se o contexto econômico em que se insere o estudo; um breve retrospecto sobre a evolução do município até o momento da implantação do porto é relatado a seguir; no terceiro item, são apresentados os resultados da pesquisa de campo para, então, no quarto e último item, discutirem-se as perspectivas do município nesta nova etapa de sua evolução econômica.

\section{Um município em processo de reconversão econômica}

O conjunto das sociedades capitalistas ocidentais, entre os anos de 1940 e 1970, vive um período de crescimento marcado pela modernização das estruturas econômicas e sociais, pela implantação, embora em graus diversos, do Estado do Bem-Estar, e pela busca da equidade econômica em escala nacional. Neste período, ganham relevo teorias e análises sobre o desenvolvimento e, em seu bojo, as voltadas ao desenvolvimento regional.

Sob a forte influência do pensamento de A. Hirschiman. F. Perroux, J. Friedemann, J.Boudeville e, em especial, da Comissão Econômica para América Latina - CEPAL, os governos dos países latino-americanos põem em prática diversas formas de ação, tendo como objetivo diminuir as disparidades inter-regionais e aumentar os níveis de consumo das populações de mais baixas rendas. No Brasil, uma forma específica dessa estratégia foi a implantação de grandes unidades produtivas em regiões periféricas de seus territórios, a maioria dos 
quais visando o desenvolvimento de atividade básicas, como a produção de aço, cobre e alumínio; a extração e produção de minerais, como petróleo e minério de ferro; a construção de barragens para a geração de hidroeletricidade; a construção de portos e vias internas de transportes.

A magnitude desses empreendimentos, em termos de recursos financeiros exigidos, das obras civis necessárias para sua implantação, dos processos de mudanças socioeconômicos provocados e, muitas vezes da geração de graves desequilíbrios ecológicos nas regiões em que se localizaram, justifica a atenção e as polêmicas que pesquisadores e planejadores dedicaram à sua avalição ao longo das décadas de 1980 e início 1990, quando boa parte desses empreendimentos entra em funcionamento ${ }^{1}$.

No Brasil, a crise econômico-financeira e a hegemonia do ideário neoliberal que chegam ao País nesse período tiram de foco as discussões sobre crescimento de longo prazo, e as medidas de política econômica voltam-se para o enfrentamento da dívida externa e o controle das taxas inflacionárias. Deste modo, a partir dos anos 1990, o país atravessa uma década de mudanças profundas em seu aparato institucional, sendo a baixa competitividade dos portos brasileiros e seus altos custos operacionais apontados como uma das barreiras à inserção do País nos fluxos comerciais e internacionais.

A partir de 2003, com o novo governo federal, são adotadas medidas que buscam retomar metas de crescimento de longo prazo. Novos e vultosos investimentos privados, contando com forte apoio do Banco Nacional de Desenvolvimento Econômico e Social - BNDES, são realizados em setores da agroindústria, na extrativa mineral, na hidroeletricidade e em infraestrutura viária, provocando um deslocamento da produção, para o Centro-Oeste e sudeste da Região Norte, ao sul do Pará. Citando apenas os investimentos no setor energético e na infraestrutura portuária, temos: a construção das usinas hidrelétricas de Jirau e Santo Antônio, em Rondônia; Belo Monte, no Pará; Teles Pires, no Mato Grosso; e Estreito, no Maranhão. Quanto aos portos, destacam-se os Complexos Industriais e Portuários de Suape, em Pernambuco e Pecém em Fortaleza-CE; o porto de Itaqui, em São Luís do Maranhão; e o Complexo Portuário do Açu, no Rio de Janeiro (Brandão, 2019).

Quanto à região de interesse do presente texto, destacam-se os investimentos da Petrobras em busca de novas jazidas de petróleo e gás nos litorais dos estados de São Paulo e Rio de Janeiro, assim como os investimentos dirigidos à indústria naval brasileira, localizada, predominantemente, na Região Metropolitana do Rio de Janeiro e ao sul do estado. No que diz respeito aos portos, com a criação da Secretaria de Portos da Presidência da República, em 2007, e a formulação do Plano Nacional de Logística Portuária, o setor passou a

\footnotetext{
1 Dentre aos autores que se dedicaram ao estudo dos impactos desses empreendimentos tem-se: Pinguelli, Luis; Lígia Sigaud. Impactos de grandes projetos hidroelétricos e nucleares, São Paulo, Marco Zero/COPPE/CNPq, 1988. Vainer, Carlo e Araújo, Frederico. Grandes projetos hidroelétricos e desenvolvimento regional. Rio de Janeiro: CEDI, 1992. Piquet, Rosélia. Reestruturação do espaço urbano e regional no Brasil. Rio de Janeiro: UFRJ/IPPUR, 1993. Grandes projetos e desenvolvimento regional. In: Petróleo e Região no Brasil: o desafio da abundância. Piquet, R. e Serra, R. (orgs) Rio de Janeiro: Garamond, 2007. Na Argentina os pesquisadores Alejandro Rofman, Elza Laurelli e Fernando Brunstein, dentre outros, dedicaram-se também ao tema.
} 
contar com grandes investimentos em novos terminais e na modernização dos portos já existentes, abrindo à iniciativa privada a possibilidade de investir e explorar os chamados Terminais de Uso Privativo.

Em dezembro de 2006, o Complexo Industrial e Portuário do Açu, localizado no município de São João da Barra, veio a ser o primeiro terminal privado do País, implantado pelo Grupo EBX, de propriedade do empresário Eike Batista. A rápida e curta evolução deste empreendimento será analisada a seguir.

\section{O mar e o rio na história de São João da Barra}

Por sua localização na foz do Rio Paraíba do Sul, desde o início de sua formação, o mar e o rio sempre desempenharam um papel central na história do município. A pesca e as atividades portuárias possibilitaram seu crescimento desde o século XVIII, quando os portugueses construíram o porto, tendo como objetivo exportar o açúcar produzido na região. Desde a circulação das primeiras embarcações, teve sua movimentação ligada aos portos de Salvador e, logo a seguir, ao do Rio de Janeiro, de Recife e de Santos, transportando a produção da região ao norte do estado do Rio, como açúcar, aguardente, café, couros, carnes e aves, para distribuição no mercado nacional. Além de se tornar importante elo na comercialização de produtos da região, atraiu também a construção naval, com estaleiros que lá se ergueram.

A prosperidade então ocorrida estimulou o crescimento da construção civil para atender à demanda de moradia das pessoas que para lá se dirigiram a fim de viverem das atividades portuárias e da construção naval. (UENF, 2014, p. 7, apud Castro, R. Dissertação de Mestrado, 2019). Em 1881, foi criada a Companhia de Navegação de São João da Barra e Campos, que dominou, por longo período, o movimento de carga e passageiros no baixo Paraíba, mantendo ligação direta com o porto do Rio de Janeiro. (Lobato, 2018, p.124, apud Castro, R. op cit).

O porto apresentava, contudo, sérios problemas causados pela instabilidade da barra, e seu canal navegável era constantemente modificado pelo assoreamento do rio. O interesse político-regional volta-se então para os transportes por estrada de ferro e pelo canal hidroviário entre Campos e Macaé. Em 1896, é inaugurada a estrada de ferro ligando a sede do município à zona de produção do açúcar, provocando, como consequência, a crise da construção naval em São João da Barra, e o município entra em fase de decadência.

A economia local passou então a depender de apenas três empresas: a Companhia Açucareira Usina Barcelos, que fabricava açúcar e álcool; o Grupo Thoquino, fabricante do conhecido Conhaque de Alcatrão São João da Barra; e a Tecex Fiação e Tecelagem, fabricante de fios e tecidos. (UENF, p.15, apud Castro,R.). Dessas empresas apenas o Grupo Thoquino permanece em atividade; a primeira delas foi desativada em 2009, e a segunda em 2008. 
A economia do município só não entrou em colapso total graças às receitas oriundas dos royalties do petróleo, que crescem a partir de 2008, ano em que também tem início a implantação das obras do Complexo Industrial e Portuário do Açu.

Esse empreendimento, inicialmente de propriedade do Grupo EBX, do empresário Eike Batista, a qual se associou a empresa de mineração Anglo American, visava implantar, em seu início, um eficiente corredor de exportação de minério de ferro oriundo de jazidas localizadas no Estado de Minas Gerais. Para tanto, em 2007, foi iniciada a construção de um mineroduto, de 530 km de extensão, atravessando 32 municípios dos dois estados até o terminal portuário no município de São João da Barra.

No Plano Diretor do Complexo Portuário, foram então previstas a operação de um terminal portuário o Porto do Açu -, com capacidade inicial de exportação de 26,6 milhões de toneladas de minério de ferro na forma de pellet-feed, e instalações portuárias para atender a navio capesize e very large ore carriers, os maiores da navegação mundial, que, até aquele momento não aportavam no País. O projeto não se restringiria apenas ao corredor de exportação mina-porto; pretendia, também, transformar-se também em um portoindústria, graças à localização, em sua retroárea, de empresas voltadas ao comércio exterior. No Plano Diretor do município, a área prevista para as atividades do Complexo era de cerca de $50 \%$ do litoral.

Assim, o pequeno município de São João da Barra, com economia de base agrícola e população de cerca de 30.000 habitantes em 2007, dos quais apenas $4 \%$ com nível superior de escolaridade, iria se tornar a sede de um empreendimento moldado nos padrões de um mundo globalizado. Os efeitos desse empreendimento não se limitariam, é claro, a esse município, cuja sede dista aproximadamente 30 km de Campos dos Goytacazes, município, na época, com aproximadamente 400.000 habitantes e que contava com uma infraestrutura de serviços capaz de atender aos trabalhadores mais qualificados.

A natureza do projeto - construção de infraestrutura portuária e de um complexo industrial voltado para a exportação - tem como característica a baixa internalização de suas atividades no local de implantação e, portanto, uma capacidade limitada de gerar encadeamentos favoráveis à dinamização da economia da região, tendendo apenas a induzir a criação de pequenos negócios ou serviços que exigem pessoal menos qualificado. Todas as informações sobre os impactos que esse empreendimento poderia desencadear na região foram apresentadas pela empresa de consultoria contratada pelo grupo EBX para realizar projeções de demanda até 2025. Não é nada modesta a demanda adicional de equipamentos que São João da Barra iria exigir. Os dados apresentados pela empresa de consultoria indicam, por exemplo, a necessidade de acréscimo 
de 995 salas de aula (na época o município dispunha de 196), 660 leitos hospitalares, contra os 36 então disponíveis, e 84.000 moradias deveriam ser acrescidas às 14.000 existentes $^{2}$.

Da parte do setor público, não houve nenhum tipo de análise a respeito dos impactos de tais investimentos. Ao contrário, a prefeita do município no dia 25/06/2008 concedeu a honraria "Medalha do Mérito de Barão de São João da Barra" ao empresário Eike Batista. Por sua vez, o Secretário de Desenvolvimento Econômico do Estado do Rio de Janeiro deste período declara: "receberemos o empreendimento de braços abertos, como o Cristo Redentor"3.

Nos anos entre o início das obras até 2013, ocorreram profundas modificações no Grupo EBX, que entra em rápido declínio, e em dezembro deste mesmo ano, o grupo norte-americano EIG Global Holding torna-se o principal acionista e assume o controle do empreendimento. Embora com atrasos, as obras portuárias foram retomadas.

\section{O Complexo Portuário do Açu e as empresas nele localizadas}

O Complexo Portuário do Açu torna-se então de propriedade da empresa Prumo Logística, controlada pelo EIG Global Energy Partners, fundo americano que opera nos setores de energia e infraestrutura e que passa a deter 91,7\% do capital, sendo a Prumo empresa que atua na gestão do Complexo Portuário.

Como o Porto do Açu está estrategicamente localizado ao norte do estado do Rio de Janeiro, próximo às bacias de Campos, de Santos e do Espirito Santos, seu posicionamento lhe confere condições de acesso marítimo e apoio logístico às empresas petrolíferas que atuam nas principais áreas de exploração e produção de petróleo e gás offshore, o que pode ser visualizado no mapa apresentado na figura 1.

\footnotetext{
2 Para aprofundamento sobre o tema, ver as dissertações de OLIVEIRA, Cláudia de. "Os laços entre estado e capital privado: o Grupo EBX como X da questão" (2012). RANGEL, Hevilmar Carneiro. "Complexo Portuário do Açu: Impacto do empreendimento no Município de São João da Barra" (2012); MAIA, Dayanne Vieira. "Porto do Açu: uma análise de conteúdo das notícias na mídia impressa regional" (2016); Produções do Programa de Mestrado em Planejamento Regional e Gestão de Cidades da Universidade Candido Mendes - Campos dos Goytacazes, RJ.)

3 PIQUET, Rosélia Perissé da Silva; SHIMODA, Eduardo. De braços abertos: As expectativas quanto aos impactos do Porto do Açu. Rio de Janeiro. Revista Política e Planejamento Regional. V.01, p. 121-137, n. 2014.
} 
Figura 1. Mapa de acesso ao Porto do Açu. Fonte: Porto do Açu, 2019

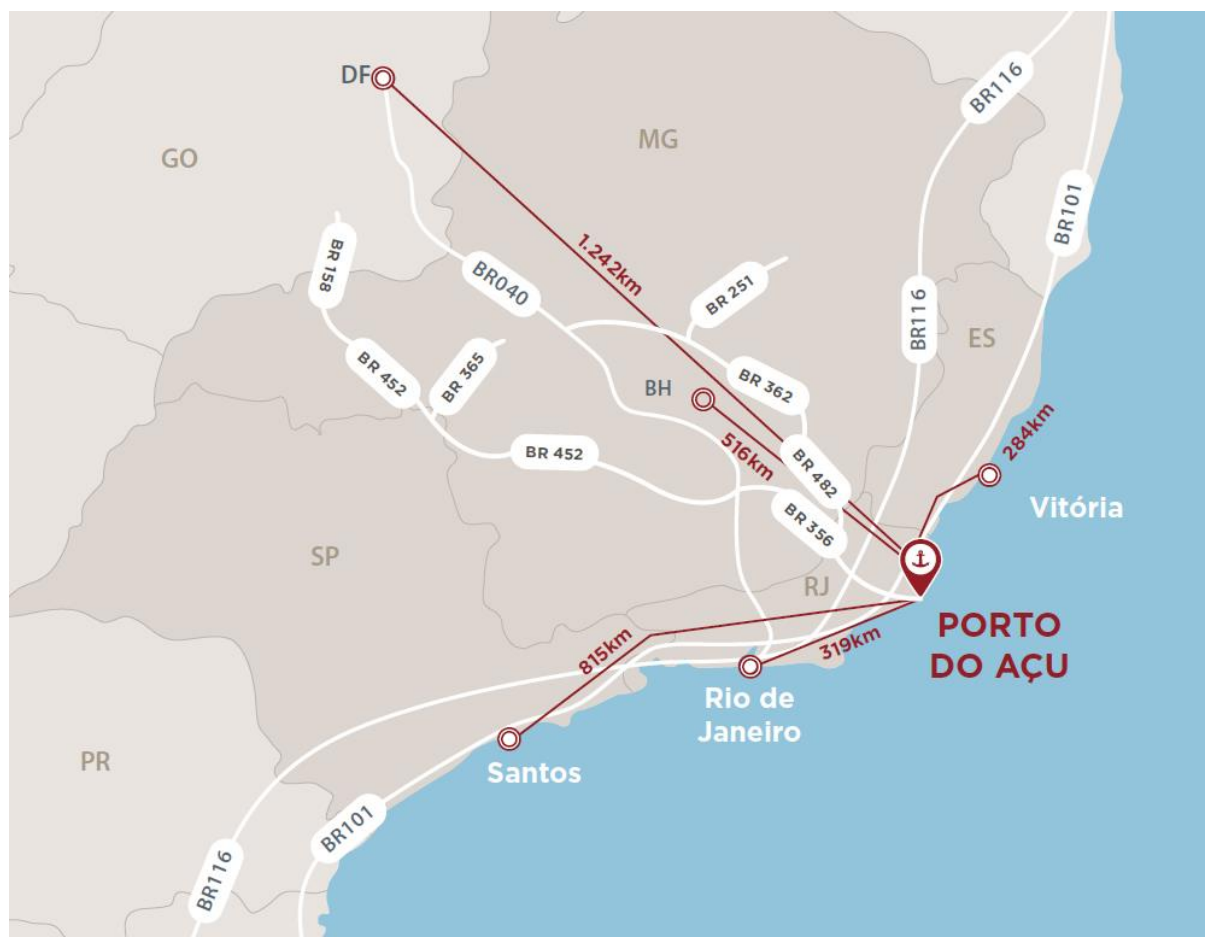

Devido à sobrecarga que já vinha ocorrendo na base de apoio offshore, localizada em Macaé e à estratégia da Prumo no sentido de fortalecer o papel do Porto do Açu como alternativa logística ao segmento de petróleo e gás, a localização de novas empresas em sua retroárea tornou-se intensa. É nesta área do porto que já se encontram localizadas 16 empresas, entre prestadoras de serviços e fornecedoras de produtos e equipamentos, dentre as quais as 12 empresas pesquisadas.

No presente, o porto dispõe de nove terminais, destacando-se o Terminal 1, dedicado à movimentação de minério de ferro e transbordo de petróleo. No Terminal 2 são operadas as cargas gerais, de outros minerais, como carvão e bauxita, e as chamadas "cargas de projetos", tais como tubulações destinadas aos serviços de prospecção e exploração em alto mar, assim como as operações de abastecimento de 64 plataformas, sendo 60 em operação na Bacia de Campos e 4 na Bacia do Espírito Santo.

\section{O posicionamento das empresas}

O roteiro das entrevistas para o levantamento de campo foi organizado em três blocos: inicialmente, constam perguntas gerais tendo como objetivo traçar o perfil das empresas pesquisadas; o segundo visa identificar as relações comerciais estabelecidas entre a empresa entrevistada e as demais empresas do porto e da região; o terceiro tem por objetivo identificar como as empresas se relacionam com as autoridades locais. 
Dado que houve compromisso sobre a não divulgação da identidade dos entrevistados, será apresentado a seguir um quadro contendo apenas o perfil desse conjunto, segundo: país de origem, início da operação no porto, atividade principal que desenvolve no Brasil e número de empregados.

Tabela 1. Relação de empresas pesquisadas no Porto do Açu. Fonte: Dados da pesquisa de campo realizada em julho de 2019

\begin{tabular}{l|c|c|c|c|l}
\hline \multicolumn{1}{c|}{ Empresa } & $\begin{array}{c}\text { Joint } \\
\text { Venture }\end{array}$ & País de Origem & $\begin{array}{c}\text { Início de } \\
\text { Operação }\end{array}$ & $\begin{array}{c}\text { No de } \\
\text { empregados }\end{array}$ & Atividade Principal \\
\hline TechnipFMC & Sim & França/EUA & 2014 & 400 & Produção de tubos flexíveis \\
\hline Petrobras & Não & Brasil & 2017 & 46 & $\begin{array}{l}\text { Logística de abastecimento das } \\
\text { plataformas de petróleo }\end{array}$ \\
\hline Anglo American & Não & Inglaterra & 2014 & 140 & $\begin{array}{l}\text { Recebimento, tratamento e } \\
\text { exportação de minério de ferro }\end{array}$ \\
\hline Andrade Gutierrez & Não & Brasil & 2018 & 3.200 & Construção civil \\
\hline Gás Natural Açu & Sim & EUA/Alemanha & 2018 & 12 & Geração de energia elétrica \\
\hline Prumo Logística & Não & EUA & 2013 & 25 & Administração Portuária \\
\hline National Oilwel Varco-NOV & Não & EUA & 2013 & 500 & Produção de tubos flexíveis \\
\hline EuroConsult & Não & Brasil & 2016 & 200 & Construção Civil \\
\hline BG Brasil & Sim & EUA/Inglaterra & 2015 & 40 & Transbordo de Petróleo \\
\hline InterMoor & Não & Brasil & 2015 & 20 & $\begin{array}{l}\text { Aluguel de armazéns e terminal } \\
\text { marítimo }\end{array}$ \\
\hline Dome Serviços Integrados & Sim & EUA/Holanda & 2017 & 50 & $\begin{array}{l}\text { Serviços diversos para } \\
\text { embarcaçães navais }\end{array}$ \\
\hline BPort (Edison Chouest) & Não & EUA & 2016 & 250 & Operação e logística offshore \\
\hline
\end{tabular}

Vê-se pelos dados constantes do quadro anterior que predominam grandes empresas que atuam em âmbito multinacional, sendo muitas delas líderes mundiais nos produtos ou serviços dos setores nos quais atuam. No conjunto das empresas pesquisadas, predominam as que prestam serviços especializados voltados à produção e ao abastecimento de plataformas e ao transbordo de petróleo.

Sete dessas empresas são de nacionalidade norte-americana, sendo 3 exclusivamente americanas e 4 em joint venture com empresas de países europeus (França, Alemanha, Inglaterra e Holanda), dentre estas, duas são grandes produtoras de tubos flexíveis aplicados na produção offshore de águas profundas e ultraprofundas dos campos petrolíferos.

Dentre as quatro empresas brasileiras, uma delas é a encarregada da construção das duas termelétricas previstas para o porto e a outra é responsável pela construção do centro de convivência (hotel, lojas e restaurantes); são, portanto, de atuação temporária no porto. As demais, uma delas trabalha com aluguel de armazéns e terminal marítimo e a outra é grande empresa nacional do setor petrolífero. 
Cabe destacar o papel da empresa Anglo American, multinacional inglesa de porte internacional, responsável na área do porto, pelo recebimento e tratamento de secagem do minério de ferro procedente de Minas Gerais para os navios de transporte internacional. Embora não empregando grande contingente de funcionários no porto, desempenhou papel histórico, pois, incialmente, o objetivo da implantação do porto foi o de ser um grande terminal marítimo de exportação de minério de ferro.

Uma vez que o porto entrou em fase operacional a partir de 2014, a data de implantação das empresas ocorre a partir deste ano, à exceção de uma das empresas, portanto, a partir do período de gestão da Prumo Logística. No total, as empresas instaladas já investiram valores superiores a R\$ 10 bilhões, segundo dados da Prumo, de 2018 (apud Rangel, 2018, p. 74).

Passando ao segundo bloco de perguntas, que visam identificar as relações comerciais com empresas da região, quando os entrevistados foram instados a informar se adquiriam produtos ou serviços localmente, cinco afirmaram que sim enquanto sete não adquiriram nada. Esta pequena diferença poderia, à primeira vista, parecer animadora em relação aos efeitos positivos que as empresas estariam exercendo sobre as empresas regionais. Contudo, quando se perguntava que tipo de produto ou serviço era demandado, as respostas invariavelmente foram: pequenas compras de material de escritório, produtos alimentícios em pequenas quantidades; e quanto à contratação de serviços, apenas os de limpeza e os de manutenção de equipamentos de escritório, tais como ar condicionado, reparos elétricos e hidráulicos. Todos afirmaram que as atividades propriamente industriais, assim como as de transporte e transbordo de óleo, devido a sua complexidade, eram atendidas por outras empresas localizadas no próprio porto ou por empresas de fora da região.

Os que responderam não comprar "nada" na região procuravam justificar argumentando que dado o seu porte ou a complexidade das operações que desenvolviam, nenhuma empresa regional apresentava condições de atender à demanda por elas exercida. Cabe destacar que os entrevistados não demonstraram estabelecer diferenciação entre os recursos (empresariais ou de mão de obra qualificada) disponíveis em São João da Barra ou em Campos dos Goytacazes, cidade que, atualmente possui cerca de 500 mil habitantes e polo regional do Norte Fluminense. A maior parte declarou adquirir os produtos do Rio ou diretamente de fábricas localizadas em outros estados. Apenas uma das multinacionais explicou que todos os insumos industriais eram provenientes da Dinamarca, pois nem sequer o Brasil os dispunha. As relações com as demais empresas do porto praticamente ocorrem apenas com a Prumo Logística, por ser a administradora do porto.

As respostas surpreendem quando são específicas quanto às relações da empresa com o setor público dos municípios: dez entre as doze empresas entrevistadas afirmaram não manter relacionamento com o setor público, a não ser os estritamente formais, exercidos por funcionários encarregados dos pagamentos de taxas 
e impostos, licenças e outras tarefas burocráticas. Apenas duas empresas afirmaram ter bom relacionamento com secretários da Prefeitura de São João da Barra.

Um ponto valorizado no levantamento de campo era o de avaliar não só o quanto as empresas ofereciam em termos de postos de trabalho, mas principalmente se existiria algum esforço de aproveitamento da mão-de-obra local como também se realizavam treinamento de pessoal. O número de postos de trabalho das empresas entrevistadas atinge 4.880 postos. Destes 1.680 em atividades permanentes e 3.200 em atividades temporárias, na construção das termelétricas e no centro de convivência. Observando-se os dados do quadro-síntese anterior, verifica-se que existe grande diferenciação entre elas quanto aos empregos gerados, indo desde 3.200 empregados até o extremo oposto de apenas 12 empregados, dado que as áreas de atuação são diferenciadas.

No que respeita ao treinamento, a quase totalidade dos entrevistados afirmou que as contratações, de modo geral, são feitas com pessoal já qualificado para as funções que irá assumir, sendo orientados durante uma ou duas semanas quanto à estrutura organizacional da empresa e aos processos específicos de trabalho. Foram citados os seguintes tipos de treinamentos específicos: trabalho em ambiente confinado, segurança em altura; trabalho com máquinas rotativas, pontes rolantes, operações de ancoragem; segurança nas tarefas em plataformas, procedimentos nas operações de transbordo. As normas desse item foram indicadas como as mais rigorosas, dada a elevada probabilidade de vazamentos perigosos quanto ao meio ambiente. Todos os entrevistados afirmaram serem as normas de segurança e a prevenção de acidentes rigorosamente exigidos de seus funcionários, por todas as empresas localizadas no porto.

Com a entrada de empresas tão distintas das até então existentes no município, torna-se evidente a ruptura que ocorreria na composição do emprego local, o que será analisado no item 4, enquanto a seguir apresenta-se a síntese das entrevistas com as lideranças políticas locais.

\section{A visão de lideranças locais}

O levantamento com representantes das administrações locais teve como objetivo identificar a visão desses agentes públicos quanto ao papel do empreendimento portuário nos municípios mais diretamente afetados. As entrevistas foram realizadas com os atuais prefeitos e os presidentes das câmaras municipais de São João da Barra e Campos dos Goytacazes e com secretários e vereadores desses municípios.

O roteiro organizado foi pautado de modo a que fosse possível identificar: a visão que essas lideranças teriam quanto às relações entre as empresas e a administração portuária com os municípios; quais as medidas adotadas neste sentido; os ônus e os bônus que o porto trouxe para os municípios ou para a região. 
Como relatado anteriormente, a implantação do projeto do porto sofreu uma ruptura quando o controle acionário do empreendimento passou do Grupo EBX, do empresário brasileiro Eike Batista, para a empresa Prumo. Deste modo uma das perguntas foi direcionada no sentido de levantar como essa mudança foi sentida pelos entrevistados. De modo geral, todos foram unânimes em afirmar terem sido surpreendidos com a notícia e que ficaram preocupados, pois temiam a interrupção das obras.

Instados a responder se houve mudanças no relacionamento entre a administração do porto e as prefeituras, o consenso é de que sim, sendo forte, significativa, distante e formal, enquanto antes era facilitado pelo próprio empresário Eike Batista. Quando solicitados a indicarem quais foram as medidas adotadas de aproximação ou de questionamento quanto ao empreendimento, apenas dois entrevistados afirmaram claramente que só a partir de 2018 a Prumo vem procurando melhorar o entendimento. Dentre as medidas objetivas realizadas por São João da Barra que foram citadas, destacam-se: o pleito de serem informados sobre os projetos das empresas e da Administração do porto, de modo a planejarem formas de atuação; a redução em $50 \%$ do ISS de empresas que comprovem a contratação de pelo menos $30 \%$ de funcionários de São João da Barra; as inciativas da Prefeitura junto ao Serviço Nacional de Aprendizagem Industrial - SENAI no sentido de melhorar a qualificação do pessoal local; a concessão de bolsas de estudo e transporte de universitários para Campos dos Goytacazes; a construção e equipagem do atual polo do Instituto Federal de Educação, Ciência e Tecnologia Fluminense - IFF, em São João da Barra. Foi ainda indicado o pleito junto à Prumo sobre o pagamento dos impostos atrasados do Imposto Predial e Territorial Urbano - IPTU.

Quanto aos demais entrevistados, as respostas foram de modo geral: vagas, superficiais, com informações incorretas; sem visão de que a importância do porto irá repercutir em toda a região. Foram unânimes em apontar a geração de empregos e o pagamento de impostos como os pontos positivos do empreendimento e a sobrecarga nos serviços de saúde, educação e transporte como os pontos negativos provocados pelo aumento populacional da região.

\section{A reconfiguração do mercado de trabalho}

Para a análise do comportamento do emprego formal em São João da Barra foram utilizados dados da Relação Anual de Informações Sociais - RAIS e do Cadastro Geral de Empregados e Desempregados - CAGED, entre 2006, ano que antecede o início da implantação do porto, e 2018.

Os dados contidos na Tabela 2 indicam movimentos distintos: em primeiro lugar, a crise econômica que afeta o País torna-se dramaticamente evidenciada quando se observa que, entre 2014 e 2018, foram fechados aproximadamente 3.200 .000 (três milhões e duzentos mil), ou seja, perda de $6,4 \%$ de postos de trabalho no 
Brasil como resultado da crise econômica que se instalou no país. No estado do Rio de Janeiro, essa perda foi de $12,6 \%$ e na Região Norte Fluminense, de $18,2 \%$.

Tabela 2. Estoque de Empregados Formais em municípios selecionados - NF, ERJ e Brasil Fonte: Dados do Ministério do Trabalho (RAIS/CAGED). Elaboração dos autores em 14/08/2019.

\begin{tabular}{|c|c|c|c|c|c|c|c|c|c|}
\hline & 2006 & 2008 & 2010 & 2012 & 2014 & 2016 & 2018* & $\begin{array}{l}\text { Variação } \\
\text { 2018/2006 }\end{array}$ & $\begin{array}{c}\text { Evolução } \\
\text { 2018/2006 } \\
\%\end{array}$ \\
\hline São João da Barra & 3.994 & 5.312 & 7.397 & 8.873 & 10.415 & 8.362 & 10.679 & 6.685 & 167 \\
\hline Macaé & 85.297 & 103.159 & 115.775 & 141.734 & 147.840 & 126.871 & 113.970 & 28.673 & 34 \\
\hline Campos dos Goytacazes & 84.224 & 88.230 & 87.380 & 93.541 & 103.218 & 90.282 & 85.405 & 1.181 & 1,4 \\
\hline $\begin{array}{l}\text { Norte Fluminense } \\
(\mathbf{x} 1.000)\end{array}$ & 188 & 211 & 227 & 260 & 281 & 243 & 230 & 42 & 22 \\
\hline Est. do RJ (x1.000) & 3.374 & 3.712 & 4.080 & 4.462 & 4.641 & 4.159 & 4.054 & 680 & 20 \\
\hline Brasil (x1.000) & 35.155 & 39.442 & 44.068 & 47.459 & 49.572 & 46.060 & 46.403 & 11.248 & 32 \\
\hline
\end{tabular}

No cenário econômico de São João da Barra entre 2014 e 2016, a redução do emprego formal foi de 19,7\%; porém esta redução ocorreu em virtude da forte desaceleração das obras de implantação do porto, que resultou na diminuição de $57,8 \%$ no número e trabalhadores na construção civil no município, conforme a Tabela 3.

Mesmo em um cenário de redução de postos de trabalho formais como o apresentado, São João da Barra mostra uma evolução diferenciada dos demais municípios da região, quando se observa o ocorrido entre 2016 e 2018. Enquanto o município recupera a oferta de postos de trabalho, esta permanece em queda em Macaé e Campos dos Goytacazes, assim como no estado do Rio de Janeiro. No caso de Macaé, a acentuada perda de postos de trabalho pode ser explicada pelo fato de que, além de ter sofrido dos mesmos problemas que afetaram a economia brasileira e o setor petrolífero, as operações de abastecimento das plataformas de petróleo da Petrobras na Bacia de Campos foram transferidas do Porto de Imbetiba, em Macaé, para o Porto do Açu. Pode-se concluir, portanto, que a recuperação de São João da Barra de 167\% na oferta de emprego, marcadamente superior aos demais municípios selecionados, ao estado e ao Brasil, indica a existência de uma força local impulsionando essa tendência e diferente daquela que acontece no mercado de trabalho nacional e estadual.

Campos dos Goytacazes, mesmo sendo limítrofe a São João da Barra e município polo da região, apresenta um crescimento de apenas 1,4\% entre 2006 e 2018, o que sugere que, até o momento, a influência proveniente da instalação do Complexo Portuário do Açu ainda é pouco aparente, o que fica confirmado 
quando se recorda que, na pesquisa de campo, foram indicadas pelos representantes das empresas, as frágeis relações comerciais das empresas do porto com esse município.

A Tabela 3 é reveladora das mudanças na estrutura do emprego em São João da Barra: enquanto em 2006, a Administração Pública e o Comércio Varejista representavam 62\% do emprego formal, em 2018, essa participação reduz-se a 36\%. Contrariamente, atividades de baixa representatividade em 2006, tais como a Indústria Química, Extrativa Mineral, Transporte e Comunicações e, Administração Técnica Profissional que perfaziam apenas $1,8 \%$ dos empregos no município, passam, em 2018, a representar 35\% do total da oferta, enquanto a Administração Pública reduz sua participação a $29 \%$.

Tabela 3. Estoque de Empregados Formais por Subsetor Econômico em São João da Barra Fonte: Dados do Ministério do Trabalho (RAIS/CAGED). Elaboração dos autores em 14/08/2019

\begin{tabular}{|c|c|c|c|c|c|c|c|c|c|c|}
\hline & 2006 & 2008 & 2010 & 2012 & 2014 & 2016 & 2018* & $\begin{array}{c}\text { Partcip. } \\
\text { Em SJB } \\
2006(\%)\end{array}$ & $\begin{array}{l}\text { Partcip. } \\
\text { Em SJB } \\
2018(\%)\end{array}$ & $\begin{array}{c}\text { Evolução } \\
\text { 2018/2006 } \\
\%\end{array}$ \\
\hline Indústria Química & 5 & 4 & 4 & 88 & 848 & 805 & 1.077 & 0,1 & 10,1 & 21.440 \\
\hline $\begin{array}{l}\text { Extrativa Mineral } \\
\text { Transporte e }\end{array}$ & 2 & 1 & 0 & 1 & 8 & 170 & 264 & 0,1 & 2,5 & 13.100 \\
\hline $\begin{array}{l}\text { Comunicações } \\
\text { Adm. Técnica }\end{array}$ & 18 & 61 & 114 & 162 & 201 & 941 & 1.145 & 0,5 & 10,7 & 6.261 \\
\hline Profission. & 44 & 63 & 143 & 312 & 256 & 376 & 1.264 & 1,1 & 11,8 & 2.773 \\
\hline Aloj. Comunicação & 190 & 277 & 358 & 538 & 580 & 470 & 403 & 4,8 & 3,8 & 112 \\
\hline $\begin{array}{l}\text { Comércio Varej. } \\
\text { Administração }\end{array}$ & 444 & 517 & 600 & 664 & 787 & 727 & 733 & 11,1 & 6,9 & 65 \\
\hline Pública & 1.997 & 2.211 & 3.583 & 2.636 & 3.970 & 2.782 & 3.080 & 50,0 & 28,8 & 54 \\
\hline Construção Civil & 281 & 1.292 & 1.747 & 3.133 & 2.676 & 1.129 & 1.619 & 7,0 & 15,2 & 476 \\
\hline Subtotal & 2.981 & 4.426 & 6.549 & 7.534 & 9.326 & 7.400 & 9.585 & 74,6 & 89,8 & 222 \\
\hline
\end{tabular}

Talvez o maior destaque a ser feito sobre o comportamento do emprego em São João da Barra seja quanto a sua participação na formação do estoque total de empregos: enquanto em 2006 participou com 2,1\% dos empregos totais da região, em 2018 dobrou essa participação, atingindo 4\%, superando todos os demais municípios da Região Norte Fluminense com exceção de Macaé e Campos que detêm, respectivamente, 50\% e 38\% dos vínculos empregatícios em 2018 (apud Castro, R. 2019, p.37) 4

Na Tabela 4, constam os dados das mudanças ocorridas nos empregos formais por grau de escolaridade em São João da Barra: enquanto em 2006 os três primeiros níveis de mais baixa qualificação perfaziam um

\footnotetext{
4 Para uma análise detalhada sobre esses dados ver Richard Castro 2019. O novo perfil do emprego em São João da Barra/RJ, sob a influência do Complexo Portuário do Açu. Dissertação de Mestrado do Programa de Planejamento Regional e Gestão da Cidade. Universidade Candido Mendes, 2019.
} 
total de 59\% de sua população, em 2018, essa participação reduz-se para $29,3 \%$. A maior participação dos níveis mais elevados de qualificação ressalta o novo perfil exigido pelas atividades do porto. Enquanto, antes da implantação do porto, não havia, no município, nenhum profissional com curso de mestrado ou doutorado, a partir de 2010, surgem os primeiros registros, atingindo o maior contingente em 2014.

Tabela 4. Estoque de Empregados Formais por Grau de Escolaridade em São João da Barra Fonte: Dados do Ministério do Trabalho (RAIS/CAGED). Elaboração dos autores em 14/08/2019

\begin{tabular}{|c|c|c|c|c|c|c|c|c|c|c|}
\hline & 2006 & 2008 & 2010 & 2012 & 2014 & 2016 & 2018* & $\begin{array}{c}\text { Partcip. } \\
\text { Em SJB } \\
2006 \text { (\%) }\end{array}$ & $\begin{array}{c}\text { Partcip. } \\
\text { Em SJB } \\
2018(\%)\end{array}$ & $\begin{array}{c}\text { Evolução } \\
\text { 2018/2006 } \\
\%\end{array}$ \\
\hline Analfabetos & 72 & 41 & 32 & 16 & 11 & 10 & 30 & 1,8 & 0,3 & -58 \\
\hline Fundam. Incompleto & 1.391 & 1.659 & 2.047 & 1.682 & 1.629 & 1.172 & 1.407 & 34,8 & 13,8 & 1,2 \\
\hline Fundam. Completo & 893 & 1.402 & 2.008 & 1.587 & 1.891 & 1.457 & 1.559 & 22,4 & 15,2 & 75 \\
\hline Médio Completo & 1.294 & 1.759 & 2.486 & 4.232 & 4.505 & 3.704 & 4.929 & 32,4 & 48,2 & 281 \\
\hline Superior Completo & 344 & 451 & 822 & 1.334 & 2.273 & 1.929 & 2.302 & 8,6 & 22,5 & 569 \\
\hline Mestrado/Doutorado & 0 & 0 & 2 & 22 & 106 & 90 & $* *$ & - & - & - \\
\hline Subtotal & 3.994 & 5.312 & 7.397 & 8.873 & 10.415 & 8.362 & 10.227 & 100 & 100 & 156 \\
\hline
\end{tabular}

É possível afirmar que essa melhoria na escolaridade do trabalhador formal decorre da presença das novas empresas que se instalaram no Complexo Portuário do Açu, uma vez que operam em segmentos como exploração e produção de petróleo e gás, indústria de transformação de alta tecnologia, operação portuária, transporte marítimo de cargas e serviços de engenharia, altamente exigentes quanto à qualificação profissional.

\section{SÍNTESE E PERSPECTIVAS}

Para se analisar a evolução de estruturas produtivas nas escalas nacional, regional ou municipal é central que se realize uma análise dos movimentos do investimento, a variável-chave do desenvolvimento econômico. É preciso verificar se ocorreu, no espaço analisado, a localização de novas plantas produtivas ou a mera ocupação de capacidade produtiva já existente, assim como se a implantação da infraestrutura de transporte e comunicação será capaz de permitir a abertura de novas frentes de comunicações inter-regionais.

O início das operações do Porto do Açu em 2014, e sua crescente consolidação como base de apoio do Complexo Petrolífero da Bacia de Campos indicam que a região ao norte do estado do Rio encontra-se marcada por grandes investimentos articulados à economia mundial e à inserção brasileira na divisão 
internacional do trabalho como exportador de commodities. As evidências empíricas aqui trazidas apontam para o fato de que a Região Norte Fluminense e, particularmente, o município de São João da Barra, encontram-se submetidos a um conjunto de mudanças que dará lugar a um intenso processo de requalificação desse espaço, seja qual for o seu resultado em termos de desenvolvimento ou não. Também ficou evidente que esse processo não é resultante de políticas públicas concebidas com tal propósito. Ao contrário, resulta de processos decisórios liderados por grandes empresas nacionais e internacionais.

Reza a literatura que trata das relações porto-cidade, que o porto indústria se caracteriza por ter pouca relação com seu entorno, suas áreas de influência são longínquas, realizam uma ocupação e uso intensivo de espaço não urbano, ocupando extensas áreas com as atividades desenvolvidas em sua retroárea, sendo este o quadro encontrado no município pesquisado 5 .

As entrevistas indicam que parte substancial dos investimentos na implantação das empresas especialmente os gastos com aquisição de máquinas, equipamentos, projetos de engenharia e mão de obra especializada - não foram, nem serão tão cedo, contratada no entorno do porto, no estado e, em alguns casos, nem mesmo no País, o que limita, e muito, a capacidade indutora desses investimentos sobre a economia local/regional.

O redirecionamento do projeto do porto quando da passagem do controle do Grupo EBX - cujo projeto de sua retroárea era baseado em empresas de setores industriais diversos, com estratégias diferenciadas para a multinacional Prumo Logística, a zona industrial perde sua feição multifuncional anteriormente prevista e passa a centrar suas atividades no processamento e na exportação do minério de ferro e, sobretudo, no apoio logístico às plataformas offshore da Bacias de Campos e do Espírito Santo. Como afirma Monié (2016) "em consequência disso, a zona industrial portuária participará de um espaço de fluxos de menor complexidade: exportação de commodities e logística de curto alcance destinada às unidades de extração de óleo".

É ponto de acordo na literatura sobre os impactos de grandes empreendimentos que os agentes mais poderosos na reestruturação do espaço têm sido as grandes corporações, cujas ações podem acentuar, em lugar de mitigar, as desigualdades regionais. Nesta mesma linha de argumentação, Becker (2006) chama atenção para o fato de que, apesar do fortalecimento da sociedade civil organizada, as redes atuais, grosso modo, reproduzem o padrão histórico de conexão das áreas produtoras aos portos, criando assim extensos

\footnotetext{
5 São numerosos os textos que versam sobre os conflitos entre as atividades portuárias e as cidades nas quais se localizam, cabendo citar: Monié, F. Vidal, M.S,C. Cidades, portos e cidades portuárias na era da integração produtiva. Revista Administração Pública, dez.2006. Monié, F. Análise geopolítica dos conflitos territoriais na área de influência do complexo portuário e industrial do Açu São João da Barra, RJ Cadernos do Desenvolvimento Fluminense n. 9, Rio de Janeiro, jan/jun 2016. Gusmão, Paulo. Apropriação e Ordenamento territorial na zona costeira no Estado do Rio de Janeiro. Revista Brasileira de Estudos Urbanos e Regionais v. 12 , n. 2. Nov. 2010. Leite, Aline e Monié, F. A geopolítica e a análise dos conflitos territoriais locais nas cidades portuárias. Anais do I Congresso Brasileiro de Geografia Política e Gestão do Território, 2014. Rio de Janeiro.
} 
territórios logísticos de escoamento, os quais têm sido mais funcionais em relação à lógica dos negócios dessas empresas do que em relação ao desenvolvimento local-regional.

Torna-se inevitável indagar sobre o papel do Estado e das políticas públicas, sobretudo na esfera dos governos locais, embora não pareça ser o momento mais oportuno de se analisar a capacidade desses agentes induzirem processos decisórios. Ficou evidente nas entrevistas dos agentes políticos e administradores locais que predomina uma visão "intramuros", localista e de curto prazo. Cada município, com seus recursos e problemas, é tratado como um caso "diferente". Falta um planejamento comum em nível estratégico para a região, assim como um diálogo que favoreça as relações entre o local e o regional, que possibilite a projeção de cenários de médio ou longo prazo.

Preocupações quanto a essas complexas questões macroeconômicas e de longo prazo parecem fora do alcance nas visões locais e, na atualidade, até mesmo fora do alcance no plano nacional. É justo encerrar reconhecendo que estabelecer uma agenda que permita o estabelecimento de propostas sobre ações e intervenções visando ao desenvolvimento desse território é tarefa que irá exigir convívio institucionalizado entre agentes públicos, produtivos e sociais, o que irá requerer esforços de médio e longo prazos e mares nem sempre fáceis de navegar. Encerrando com um pouco de leveza:

\footnotetext{
Mas, afinal, o que é um porto? A resposta parece fácil: o lugar protegido dos ventos e dos mares, à beira de um oceano, mar, lago ou rio, onde as embarcações podem entrar e sair, flutuar e ancorar, carregar e descarregar pessoas ou coisas. A resposta, no entanto, será mais complexa se recordarmos as inúmeras possibilidades de um porto. A primeira delas é que nem sempre se trata de um porto natural, lugar de abrigo e ancoragem oferecido pela natureza em um acidente geográfico qualquer. Os dicionários trazem outras definições para esse cenário onipresente na história humana: portos de arribada, de carga, de comércio, de escala, de quarentena, de refúgio. Já o porto artificial, eles nos informam, é aquele construído pela mão do homem para servir ao comércio ou à guerra que, afinal, movimentam a História. Por fim, quando pensamos nos sentidos figurados atribuídos à palavra, o nosso imaginário se transporta para toda sorte de proteção oferecida por um porto seguro. (Maria Inêz Turazzi, 2016).
}

\section{REFERÊNCIAS}

ANGELIS, Ângelo. Guerra Fiscal dos Portos e Desenvolvimento Regional no Brasil. Revista de Desenvolvimento Regional, Santa Cruz do Sul. V. 18, n.1 pag, 185 -212, jan/abril 2013.

BRANDÃO, C. A. Mudanças produtivas e econômicas e reconfiguração territorial no Brasil no início do século XXI. Revista Brasileira de Estudos Urbanos e Regionais. São Paulo: v. 21, n.2 maio/agosto de 2019. Pg 258-279.

BECKER, Berta (coord). Logística e Ordenamento Territorial. Relatório preparado como subsídio à elaboração da Política Nacional de Ordenamento Territorial - PNOTT, 2006.

BRASIL. Ministério da Economia. Secretaria de Trabalho. Bases Estatísticas RAIS e CAGED. Disponível em: <http://bi.mte.gov.br/bgcaged/inicial.php>. Acesso em 14/08/2019.

CASTRO, Richard. O novo perfil do emprego em São João da Barra: um estudo sobre a influência da implantação de um grande empreendimento, o Complexo Portuário do Açu. Dissertação de Mestrado, Universidade Candido Mendes, 111 p. Programa de Mestrado e Doutorado em Planejamento Regional e Gestão da Cidade, setembro, 2019. 
GUSMÃO, Paulo. Apropriação e Ordenamento Territorial na Zona Costeira do Estado do Rio de Janeiro. Estudos Urbanos e Regionais, v.12, n.2, novembro de 2010.

MONIÉ, Frédéric. Análise geopolítica dos conflitos na área de influência do complexo portuário e industrial do Açu - São João de Barra, RJ. Cadernos do Desenvolvimento Fluminense, n. 9, Rio de Janeiro, pp169-83, jan/jun 2016.

MONIÉ, F. Dinâmicas Produtivas, Logística e Desenvolvimento Territorial. In: Videira, S. L.; Costa, P. A. e Fajardo, S.(0egs) Geografia Econômica: (re)leituras contemporâneas. Rio de Janeiro: Letra Capital,2011.

MONIÉ, F. e Vasconcelos, F. Evolução das relações entre cidades e portos: entre lógicas homogeneizantes e dinâmicas de diferenciação. Revue franco-beésilienne de géographie. N. 15, 2012.

PORTO DO AÇU. Mapa de acesso ao Porto do Açu. Disponível em: <https://portodoacu.com.br/fotos/>. Acesso em 25/04/2019.

TURAZZI, Maria Inêz. Rio, um porto entre dois tempos: modos de ser, modos de conhecer. Rio de Janeiro: Bazar do Tempo, 2016.

Universidade Estadual do Norte Fluminense Darcy Ribeiro - UENF. Conhecendo a História de São João da Barra - Projeto de Extensão - Coordenação: Prof. Alcimar das Chagas Ribeiro - São João da Barra, janeiro/2014. 